\title{
SEDAÇÃO PALIATIVA DO PACIENTE IDOSO: ESTUDO TRANSVERSAL SOBRE SEDAÇÃO PALIATIVA EM HOSPITAIS DE PORTO ALEGRE
}

\author{
Alessandra Santos Menin, ULBRA, alesmenin@gmail.com \\ Paulo Roberto Cardoso Consoni, ULBRA, consoniconsoni@gmail.com
}

\section{RESUMO}

Introdução: Em razão do crescente número de idosos e, consequentemente, de pacientes em final de vida, é imprescindível compreender o emprego da sedação paliativa na hipótese de refratariedade de possíveis sintomas de sofrimento físico, psicoemocional ou espiritual, com vistas a propiciar uma morte digna. Objetivo: Conhecer a prática da sedação paliativa do paciente idoso em hospitais com serviço de cuidados paliativos de Porto Alegre. Métodos: Trata-se de estudo transversal, realizado em 2019, por meio de entrevistas não estruturadas com médicos geriatras que atuam na área de cuidados paliativos em dois hospitais de Porto Alegre. Resultados: O primeiro entrevistado sustenta que a sedação paliativa é o recurso final para o paciente, devendo ser utilizada para dar conforto, aliviar ansiedade e dor, progredindo na linha de cuidados, quando o paciente apresenta sintomas intratáveis que geram sofrimento. Refere, ainda, que jamais deve ser utilizada para acelerar o processo de morte, demandando o envolvimento da equipe médica entre si, com o paciente e seus familiares. $\mathrm{O}$ segundo entrevistado, por sua vez, afirma que a sedação deve ser feita quando há sofrimento intratável em todas as esferas da dor ("Dor Total"), sendo a sedação a última alternativa a ser recorrida. $O$ sofrimento do paciente deve ser abordado como um todo, com atenção psicológica e espiritual. Conclusão: Conclui-se que ambos os serviços utilizam a sedação paliativa como ferramenta de último recurso, recorrendo-se apenas quando não há outra alternativa possível nos casos de sintomas refratários, o que está em consonância com a literatura médica sobre o tema.

Palavras-chave: Sedação Profunda; Cuidados Paliativos; Idoso; Geriatria. 